San Jose State University

SJSU ScholarWorks

Master's Theses

Master's Theses and Graduate Research

1998

\title{
Hamstring strain prediction from hamstring/quadriceps strength ratio in soccer
}

Dawn A. Carter

San Jose State University

Follow this and additional works at: https://scholarworks.sjsu.edu/etd_theses

\section{Recommended Citation}

Carter, Dawn A., "Hamstring strain prediction from hamstring/quadriceps strength ratio in soccer" (1998). Master's Theses. 1626.

DOI: https://doi.org/10.31979/etd.qztv-rse7

https://scholarworks.sjsu.edu/etd_theses/1626

This Thesis is brought to you for free and open access by the Master's Theses and Graduate Research at SJSU ScholarWorks. It has been accepted for inclusion in Master's Theses by an authorized administrator of SJSU ScholarWorks. For more information, please contact scholarworks@sjsu.edu. 


\section{INFORMATION TO USERS}

This manuscript has been reproduced from the microfilm master. UMI films the text directly from the original or copy submitted. Thus, some thesis and dissertation copies are in typewriter face, while others may be from any type of computer printer.

\section{The quality of this reproduction is dependent upon the quality of the} copy submitted. Broken or indistinct print, colored or poor quality illustrations and photographs, print bleedthrough, substandard margins, and improper alignment can adversely affect reproduction.

In the unlikely event that the author did not send UMI a complete manuscript and there are missing pages, these will be noted. Also, if unauthorized copyright material had to be removed, a note will indicate the deletion.

Oversize materials (e.g., maps, drawings, charts) are reproduced by sectioning the original, beginning at the upper left-hand corner and continuing from left to right in equal sections with small overlaps. Each original is also photographed in one exposure and is included in reduced form at the back of the book.

Photographs included in the original manuscript have been reproduced xerographically in this copy. Higher quality 6" $\times 9$ " black and white photographic prints are available for any photographs or illustrations appearing in this copy for an additional charge. Contact UMI directly to order.

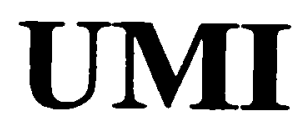

A Bell \& Howell Information Company 



\title{
HAMSTRING STRAIN PREDICTION FROM HAMISTRING/QUADRICEPS STRENGTH RATIO IN SOCCER
}

\author{
A Thesis \\ Presented to \\ The Faculty of the Department of Human Performance \\ San Jose State University
}

in Partial Fulfillment

of the Requirements for the Degrec

Masters of Arts

By

Dawn A. Carter. A.T..C.

May 1998 
UMI Number: 1389637

UMI Microform 1389637

Copyright 1998, by UMI Company. All rights reserved.

This microform edition is protected against unauthorized copying under Title 17, United States Code.

\section{UMI \\ 300 North Zeeb Road \\ Ann Arbor, MI 48103}


$=$ 


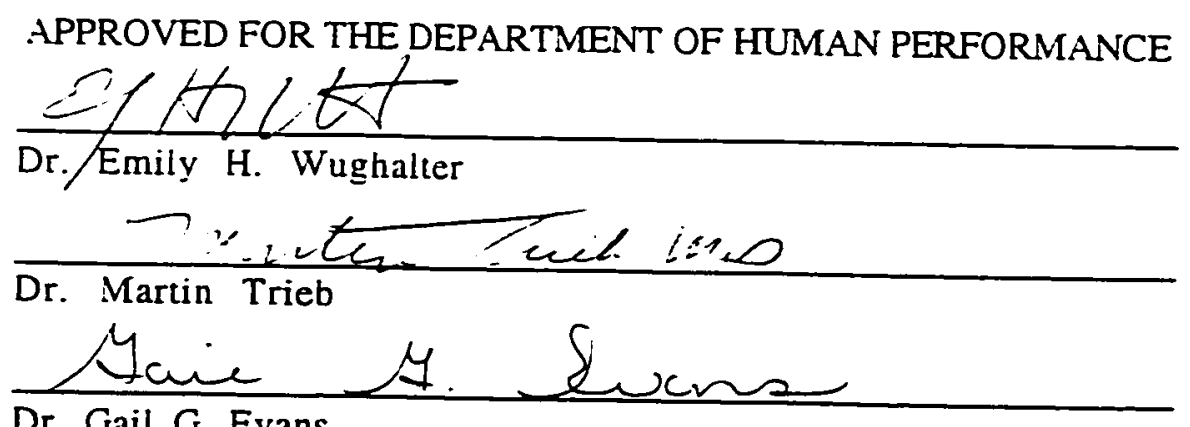

Dr. Gail G. Evans

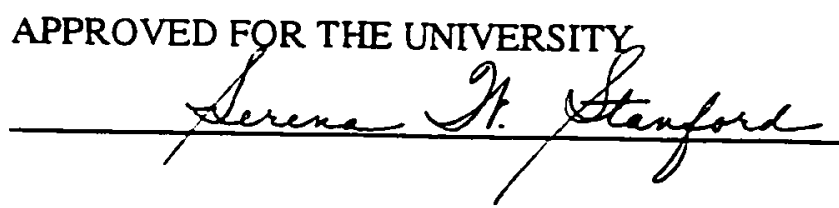




\section{ABSTRACT \\ HAMSTRING STRAIN PREDICTION FROM HAMSTRING/QUADRICEPS STRENGTH RATIO IN SOCCER}

by Dawn A. Carter

The purpose of this study was to examine the peak torque of the hamstrings and quadriceps to determine if significant isokinetic strength ratio imbalance existed between the anterior and posterior thigh muscle in collegiate men's and women's soccer athletes with and without hamstring strain, and to conclude if there was a correlation between hamstring/ quadriceps strength ratio imbalances and occurrence of hamstring strain. Twenty-eight participants (12 male, 16 female) comprised the test sample. The participants were prospectively tested on a Cybex II at angular velocities of $60 \%$, $120 \%$, and $180 \%$ s. Hamstring injuries that resulted from participation on San Jose State University soccer teams were recorded throughout the competitive season. One left leg dominant male athlete experienced a hamstring strain during the season. Therefore. the null hypotheses could not be parametrically tested. so a point biserial correlation test was performed. The point biserial correlations were not statistically significant. 


\section{ACKNOWLEDGEMENTS}

The author wishes to extend sincere gratitude to Dr. Emily Wughalter for her willingness to come on board at a late date and her dedication to this project. Special thanks are expressed to the other members of the committee: Dr. Martin Trieb for his sacrifice and time commitment, and Dr. Gail Evans for her patience and understanding.

Other thanks to Dr. Bethany Shifflett for her statistical expertise, Eileen Wunder A.T.,C. for her assistance with the testing, and Jeb Burns A.T.,C. and Charlie Murdach A.T.,C. for their constant support and friendship. Special thanks are also expressed to Dr. Robert Kersey and Dr. Jack Ransone for their initial guidance with the project.

Sincere love and thanks are extended to my entire family and all my friends. for without your encouragement, sacrifice, and love. none of this would be possible. Thank you for helping me follow my dreams. 


\section{DEDICATION}

This thesis is dedicated to my grandmother. "Maw". for her endless love and support. I know that I lost valuable time with you while I was following my dreams. but you were never far from my thoughts. Thank you for your love. laughter. and support. I love you "a bushel and a peck!" 


\section{TABLE OF CONTENTS}

Abstract.

Acknowledgements

iv

Acknowledgements

Dedication

vi

Table of Contents.

Chapter 1 .......

Introduction.

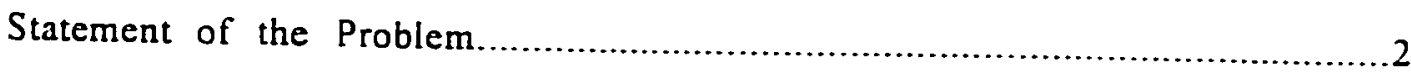

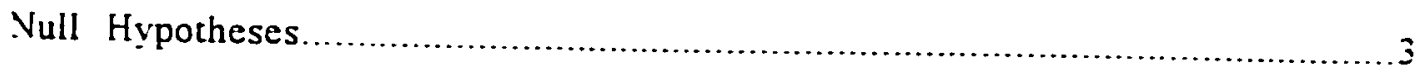

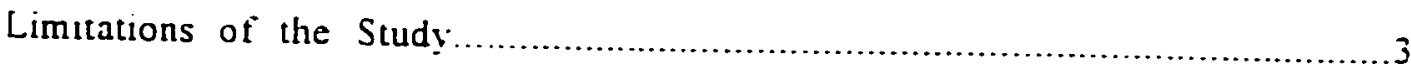

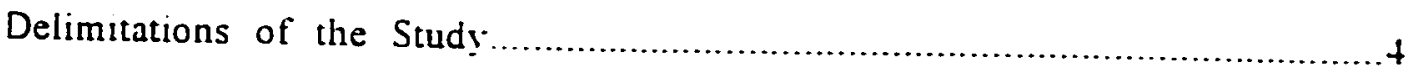

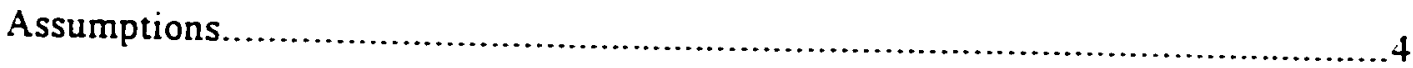

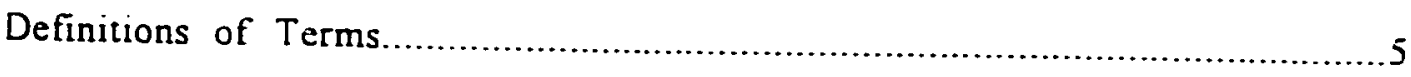

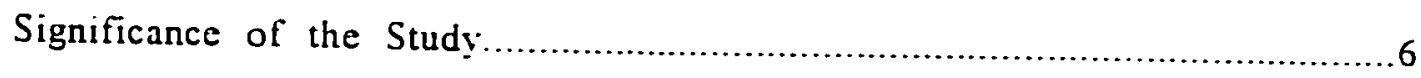

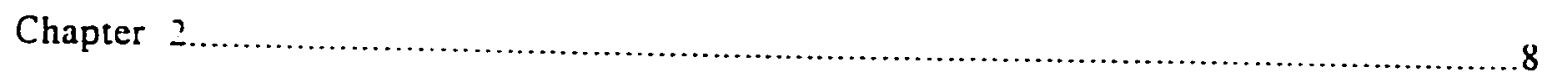

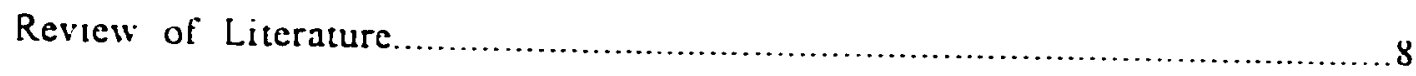

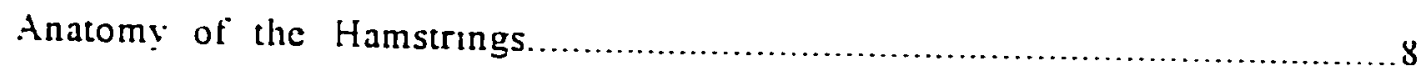

Biomechanics of the Hamstrings...................................................... 10

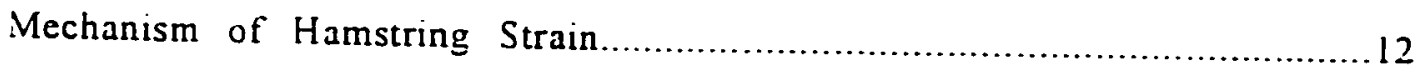

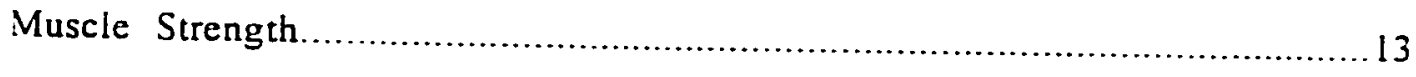

Hamstring/Quadriceps Strength Ratio......................................... 15

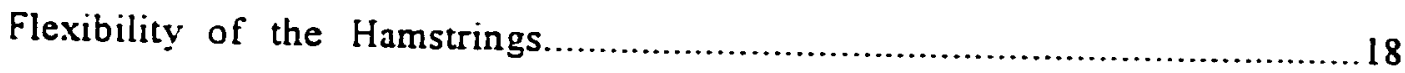

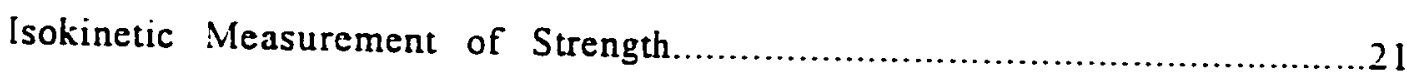

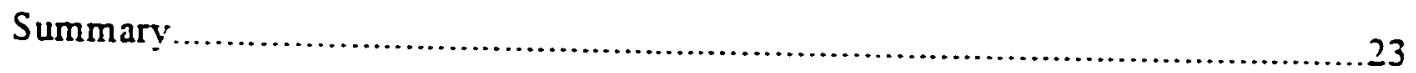




\section{Chapter 3}

Methods.

Particpants.

Apparatus.

Procedures.

Design

Analysis of Data.

Summary

Chapter 4

Results

Table 1

Table 2 .

Table 3

Supplementary Analysis

Table 4 .

Summary:

Chapter 5

Discussion and Conclusion.

Discussion

Weaknesses of the Study:

Recommendations for Future Studies.

Conclusion.

References.

Appendix A.. 
Appendix B

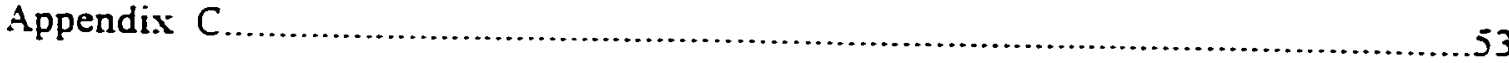

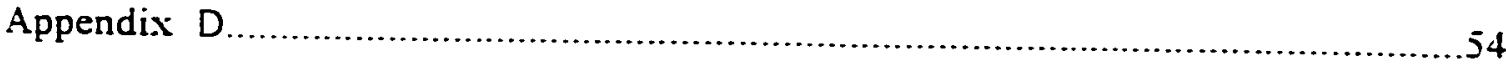

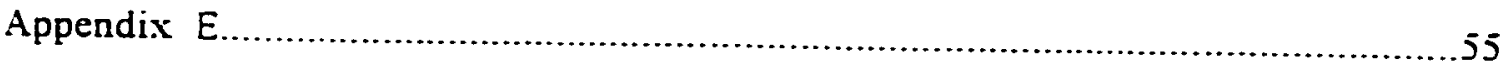

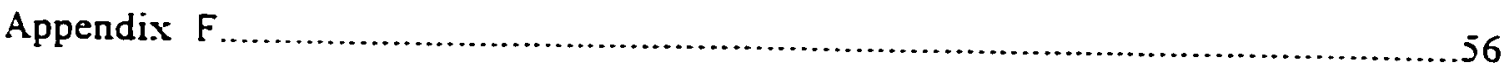

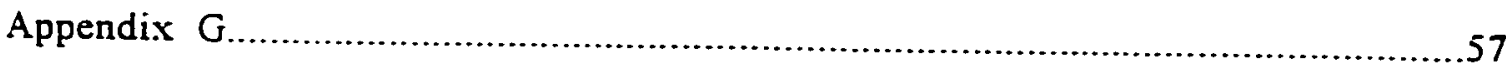




\section{Chapter I}

\section{INTRODUCTION}

Hamstring strain can be one of the most debilitating sports injuries. The hamstrings (biceps femoris. semitendinosus. and semimembranosus). agonists to the quadriceps. primarily function as knee flexors and secondary hip extensors (Booher \& Thibodeau, 1994). The hamstrings are the most commonly strained thigh muscles. Usually a hamstring strain results in a loss of time from activity, requires slow recovery, and has a high rate of recurrence (Agre. 1985: Coole \& Geick. 1984: Fried \& Llovd. 1992: Shankman. 1993: Sutton. 1985: Vorrell \& Perrin. 1992). Hamstring strain is commonly a noncontact injury with two possible onsets: 1) sudden onset with immediate sharp pain or 2) slow insidious onset associated with muscle tightness (Worrell. 1994). Muscle injury usually occurs at the beginning or toward the end of activity and can be the result of poor warm up. fatigue. inadequate tlexibility. muscle asymmetry. or muscle imbalance.

The hamstrings have several functions during the running gait. They decelerate the leg during the forward swing phase. extend the hip and stabilize the knee during the support phase. and assist the gastrocnemius in extending the knee during take off (Shankman. 1993: Sutton. 1984). During these complex actions the hamstrings are put under enormous stress. At foot strike the hamstrings are elongated, then during the support phase they concentrically contract. and after take off they eccentrically contract. A hamstring strain may occur if any part of this complex action is interrupted by a decrease in flexibility. an imbalance of the hamstring/quadriceps strength ratio. or an abnormal contraction. Several studies examining muscle strength and its effect on hamstring strain have been conducted. Morris. 
Lussier. Bell. and Dooley (1983) and Zakas. Mandroukas. Vamvakoudis. Christoulas, and Aggelopoulou (1995) conducted research that was retrospective. Burkett (1970). Christensen and Wiseman (1982). Liemohn (1978), Morris et al. (1983). and Yamamoto (1993) studied track and field athletes specifically. A prospective approach to the research and further inquiry into sports other than track and field is needed.

Soccer is fast becoming the most popular sport in the world (Ekstrand \& Gillquist. 1982: Ekstrand \& Gillquist. 1983a. 1983b: Inklaar, 1994: Nielsen \& Yde, 1989). Increased popularity and participation in soccer have contributed to an increased potential for injuries. Prior research supported an increased incidence and severity of injury as competition levels increase (Ekstrand \& Gillquist: Ekstrand \& Gillquist. 1983a: Nielsen \& Yde: Zakas et al.. 1995). Studies of soccer players (Ekstrand \& Gillquist: Ekstrand \& Gillquist. 1983a. 1983b:

Nielsen \& Yde: Zakas et al.. 1995) have focused on elite and international teams. Little emphasis has been applied to a collegeiuniversity setting or to United States soccer teams.

\section{Problem Statement}

Hamstring strains are common injuries of the thigh that occur in soccer (Ekstrand \& Gillquist. 1982: Ekstrand \& Gillquist. 1983a: Nielsen \& Yde. 1989. Zakas et al.. 1995). Often these injuries are followed by a long recovery with a high rate of re-injury. By examining isokinetic strength of the anterior and posterior thigh musculature. this study investigated the extent to which muscle strength imbalance contributes to the occurrence of hamstring strain. By understanding more about muscle imbalance preventative strength programs can be designed for athletes. possibly preventing injury. Also. 
comprehensive rehabilitation programs can be developed once a hamstring strain has occurred.

Due to the emergence of soccer as one of the most popular participation sports. a prospective study was designed to examine the role of muscle imbalance on hamstrings muscle strain in college soccer players. The purpose of this study was to examine the peak torque of the hamstrings and quadriceps to determine if significant isokinetic strength ratio imbalance existed between the anterior and posterior thigh muscle in collegiate men's and women's soccer athletes with and without hamstring strain. and to conclude if there ivas a correlation between hamstring/quadriceps strength ratio imbalances and occurrence of hamstring strain.

\section{Null Hvootheses}

The following null hypotheses were developed for the purpose of the research:

1. Hamstrings and quadriceps isokinetic peak torque will not combine to predict hamstring strain in collegiate soccer players.

2. Hamstring isokinetıc peak torque will not relate to hamstring strain in collegiate soccer players.

3. Quadriceps isokinetic peak torque will not relate to hamstring strain in collegiate soccer players.

\section{Limitations of the Studv}

The study was limited in the following ways:

1. The sample was composed of volunteers from the 1997 San Jose State University men's and women's soccer teams. Participants were selected only if they were present on the first day of practice. 
2. The amount. frequency. intensity. duration and type of training and/or conditioning of the players in the offseason was not controlled. The athletes are given off season strength and endurance programs. but the participants were not asked if or how closely they followed the program.

3. Gravity effect was not corrected. A gravity correction on an isokinetic device requires removing the effects of gravity from test scores.

\section{Delimitations of the Studv}

1. The participants selected for inclusion in the study had no history of hamstring strain in the three months prior to the day of testing. This was necessary to prevent a previous injury from being included in the study.

2. Participants had no current history of chronic or acute inflammatory conditions of the knee. unrepaired meniscal lesions, rotary instability, or gout. The aforementioned current and chronic conditions were deemed to predispose an athlete to hamstring strain.

3. Participants were advised to drive to the test site in an attempt to control the amount of warm up. however. mode of transportation was not directly controlled. Warm up was performed at the test site in an attempt to provide equal warm up for each participant: prior warm up was discouraged.

4. Injuries were evaluated and recorded by a National Athletic Trainers' Association. Board of Certification. Inc.. Certified Athletic Trainer. A Certified Athletic Traner craluated and recorded the hamstring strain to ensure accurate assessment.

\section{Assumptions}

1. Participants complied with pretest requirements. 
2. Participants responded honestly to the medical history questionnaire and orthopedic screening.

3. Participants gave maximal effort during isokinetic strength testing.

4. Participants reported hamstring strain once symptoms were experienced and reported only those injuries that occurred during participation in soccer at San Jose State University. Strains that did not occur during practice. games. or fitness exercises were not measured for this study. Definition of Terms

Athletic injurs A disruption of tissue continuity that results from athletic or sports-related activity. causing a cessation of participation or restriction of usual actirity (Amheim \& Prentice. 1994). For the purpose of this study an injury was recorded as missing one day of practice or a game following the initial onset (Agre. 1985: Arnheim \& Prentice. 1994: Booher \& Thibodeau. 1994: Ekstrand \& Gilquist. 1982: Inklaar. 1982).

Hamstring/quadriceps strength ratio Hamstring/quadriceps strength ratio is a comparison of knee flexor strength relative to knee extensor strength to determine muscle imbalance (Aagaard. Simonsen. Trolle. Bangsbo \& Klausen. 1995: Burkett. 1970: Morris et al.. 1983: Yamamoto. 1993). For the purpose of this study isokinetic strength at three angular relocities $(60 \%$ s. 120\% $180 \% / \mathrm{s})$ was measured to provide the hamstring/quadriceps strength ratio. Isokinetic strength. Isokinetic strength is measured as torque produced through full range of motion with accommodating resistance (Cybex Manual. 1983). Isokinetic strength is a dynamic measure. For the purpose of this study isokinetic strength was measured in foot/pounds ( $f \cdot / b)$ then converted to Newton/meters $(\mathrm{N} \bullet \mathrm{m})$. 
Lumbar. Lumbar nerves are abbreviated as $(L)$ and the number of the nerve. For the purpose of this study L5 stands for the fifth lumbar nerve (Arnheim \& Prentice. 1994.)

Muscle strength. Muscle strength a measure describing an individual's ability to exert a maximal muscular force against resistance, either statically or dynamically (Moss \& Wright, 1993). For the purpose of this study muscle strength was measured isokinetically in $\mathrm{ft} \cdot \mathrm{lb}$ then converted to $\mathrm{N} \bullet \mathrm{m}$. Muscle strain. A muscle strain is an injury involving the musculotendinous unit, the muscle belly, or the attachment to the bone (Booher \& Thibodeau, 1994). For the purpose of this study muscle strain was evaluated and determined by the Certified Athletic Trainer if the participant missed one day of practice or a game following the injury.

Open kinetic chain. Open kinetic chain exercises are exercises in which motion at the knee is independent of motion at the hip and ankle. For the purpose of this study open kinetic chain exercises are those where the distal segment is free to move (Brotzman, 1996).

Sacral. Sacral nerves are abbreviated as (S) followed by the number of the nerve. For the purpose of this study S1, S2, and S3 stand for the first, second, and third sacral nerves (Arnheim \& Prentice. 1994).

\section{Significance of the Studv}

This research study was significant because it examined the hamstring/quadriceps strength ratio prospectively. [sokinetic testing was conducted prior to the season and hamstring strain was monitored throughout the season to determine the efficacy of hamstring/quadriceps strength ratio in nredictino hamstrino strain Rv examining Inited States interconllegiate. 
soccer players comparisons can be made with other populations. This study was unique in that it examined both men's and women's soccer players.

The National Collegiate Athletic Association (NCAA) conducted an injury survey in 1996 that detailed the injuries for intercollegiate men's and women's teams. The data for thigh injuries were not separated by hamstrings or quadriceps, however out of 111.887 exposures 216 reported thigh injuries were for the women and out of 138.769 exposures 210 reported thigh injuries were for the men. The NCAA survey also provided categories of injury. Strains were listed. but the data were not specific to where the strain occurred. Three hundred and sixty-seven strains were reported by women and 345 strains were reported by the men throughout the 1996 soccer season. These data failed to uncover how many intercollegiate men's and women's soccer plavers incur hamstring strain.

The 1996 San Jose State men's and women's teams reported seven hamstring strains during the season. The 1997 men's and women's team's training schedules and fitness and weight lifting programs were similar to those from the 1996 season. The change that could have affected the injur: rate for 1997 was the addition of a strength and conditioning coach to implement and monitor the fitness and weight training programs for the women's team.

The NCAA's data along with the 1996 San Jose State injury records for the men's and women's soccer teams that reported seven hamstring strains. raised the suspicion that multiple hamstring strains could occur during the 1997 San Jose State soccer seasons. 
Chapter 2

\section{REVIEW OF LITERATURE}

The hamstrings are one of the most complex sets of muscles in the body. due to its role in locomotion and stabilization of the lower body. The hamstrings are generally thought to consist of three muscles that span from the hip to the knee on the posterior aspect of the thigh. These muscles are the biceps femoris. semitendinosus. semimembranosus. Coole and Geick (1987) identify the adductor magnus as a possible fourth hamstring muscle. The following review of literature details the anatomy and biomechanics of the hamstrings, mechanisms of injury for a hamstring strain. hamstrings and quadriceps muscle strength. the hamstring/quadriceps strength ratio. hamstrings flexibility, and isokinetic testing.

\section{Anatomv of the Hamstrings}

The biceps femoris lies posterior and lateral in the thigh and as its name indicates has a long head and a short head (Agre. 1985: Casperson \& Kaverman. 1982: Coole \& Geick. 1987: Sutton. 1984). The long head of the biceps femoris originates on the ischial tuberosity and inserts on the fibular head. The short head arises from the linea aspera of the femur and also inserts on the fibula. The long and short heads receive separate innervation. The long head of the biceps is innervated by the tibial portion (L5. SI. S2. S3) of the sciatic nerve. The short head of the biceps is innervated by the peroneal portion (L5. SI. S2) of the sciatic nerve (Casperson \& Kaverman: Coole \& Geick). When the two heads of the biceps femoris function together they produce knee flexion. lateral rotation, and hip extension. 
The semitendinosus lies on the posterior medial aspect of the thigh as it diverges from its common origin with the long head of the biceps femoris (Coole \& Geick. 1987: Sutton. 1984). The semitendinosus originates at the ischial tuberosity and inserts on the anterior medial aspect of the tibia. This insertion is shared with the sartorius and gracilis and is referred to as the pes anserine (Coole \& Geick). The primary movement of the semitendinosus is simultaneous knee flexion and hip extension. Other actions are medial rotation of the knee and medial rotation and adduction of the hip (Coole \& Geick: Shankman. 1993: Sutton). The semitendinosus is innervated by the tibial portion of the sciatic nerve (Casperson \& Kaverman. 1982: Coole \& Geick).

The semimembranosus lies directly under the semitendinosus and attaches to the posterior medial aspect of the tibia (Thompson. 1994). As it passes posterior to the knee it lends a thick band of connective tissue and blends with the posterior capsule. The semimembranosus also flexes the knee and extends the hip and medially rotates and adducts the hip ICoole \& Geick. 1987: Shankman. 1993). The semimembranosus is innervated from the tibial portion of the sciatic nerve 1 Casperson \& Karcrman. 1982: Coole \& Geick).

The adductor magnus is not typically classified as a hamstring muscle. However. its origin. action. and innervation warrant it being mentioned under hamstring anatomy (Coole \& Geick. 1987). The posterior portion of the adductor magnus originates from the ischial tuberosity and inserts on the adductor tubercle (Coole \& Geick). The adductor magnus functions in hip extension and rotation of the hip (Casperson \& Kaverman. 1982: Coole \& Geick). Innervation of the adductor magnus stems from the sciatic nerve. the same nerve that supplies the semitendinosus. semimembranosus. and long head of the biceps femoris (Coole \& Geick). 
The hamstrings consists of three biarticular muscles that are the biceps femoris. semitendinosus. and semimembranosus. with some recognition of a fourth- the adductor magnus. The hamstrings are complex muscles that actively create many motions. The hamstrings flex the knee. extend the hip. lateral and medial rotation of the knee. and adduct the hip.

\section{Biomechanics of the Hamstrings}

Previously discussed were the actions of the hamstrings in a nonweight bearing, open kinetic chain. As previously defined an open kinetic chain is when the motion of the knee is independent of the motion at the hip and ankle. The hamstrings have four functional capacities during running. including: 1) thexion of the knee. 2) deceleration of the forward swing phase. 3) extension of the hip and stabilization of the knee during the support phase. and f) assistance to the gastrocnemius in extending the knee during take off (Shankman. 1993: Sutton. 1984).

The hamstrings have different functions during the two different phases of running. The support phase consists of three phases: foot strike. midsupport. and take off (Cooke \& Geick. 1987). As the hip and the knee prepare for the support phase the hamstrings contract eccentrically to limit knee extension and hip flexion and then concentrically contract to flex the knee and extend the hip (Coole \& Geick). An electromyographic analysis of running gait by Elliott and Blansky (1979) measured the role of each hamstrings. They found beginning with foot strike, the biceps femoris and semimembranosus contract to provide knee flexion and hip extension to stabilize the knee. During midsupport the semitendinosus is contracted to add knee stabilization and hip extension. The biceps femoris has a maximal 
contraction and the semimembranosus and semitendinosus maintain their strong contraction just prior to take off. The recovery phase is described in three phases: follow through. forward swing, and foot decent (Coole \& Geick). After take off. the follow through phase occurs due to a shift in the inertial phase. making it a nearly passive activity. The forward swing of the recovery phase shows an increase in semimembranosus activity. This causes a deceleration of the thigh through eccentric contraction.

Sutton (1984) described the hamstrings as having multiple functions during the running gait cricle. On foot strike the hamstrings are elongated to provide for optimal contraction during the midsupport phase. A concentric contraction allows the hamstrings to extend the hip and flex the knee to provide stabilization. During toe off the quadriceps muscle provides primary knee extension. Sutton stated. "In a closed kinetic chain. at 20 degrees from terminal extension the yastrocnemius and hamstrings create a paradoxical extension of the knee as the mechanical adrantage of the quadriceps decreases" (p. 188). After take off the hamstrings eccentrically contract to decelerate the lorward swing of the leg. This action prepares the leg for foot strike and enables the cycle to continue.

Shankman (1993) explained the importance of concentric and eccentric contraction during high speed limb movement. He stated during high speed contractions eccentric contraction plays a critical role. During the running cycle eccentric contraction is immediately followed by concentric contraction. Concentric forces generated in this manner are increased. This reciprocal function is necessary to produce speed and strength during knee flexion and hip extension. 


\section{Mechanism of Hamstring Strain}

Hamstring strains are caused by one or more of the following factors: fatigue. failure of the reciprocal action of the hamstrings and quadriceps muscles. decreased hamstring/quadriceps strength ratios. lack of hamstrings flexibility, and/or muscle breakdown due to the complex contractions of the hamstrings (Agre. 1985: Casperson \& Kaverman. 1982; Christensen \& Wiseman. 1972: Coole \& Geick. 1987: Shankman. 1993: Sutton. 1984: Worrell \& Perrin. 1992). "Muscle tears will most likely occur when a rapid maximal contraction occurs in a fully elongated muscle" (p.187). Any strain injury involves the tearing of muscles and conncctive tissue. Strains can be as mild as microtears in the muscle to complete ruptures of the musculotendinous unit or in the belly of the muscle. The amount of damage and loss of time determines the severity of the injury (Dr. John Powell. personal communication. April 2. 1997).

Sutton (1984) suggested hamstring strains occur as a result of an abnormality in the reciprocal action of the hamstrings and quadriceps muscles. During movement if the hamstrings are called upon before the stabilizers can relax there is usually a strain of the stabilizer muscles-the biceps femoris and the semimembranosus. Sutton also stated "excessive external stretch placed on a relaxed muscle is an element of injur:" (p.187).

Shankman (1993) described two theories for the mechanism of hamstring strain. He agreed with most authors (Burkett. 1970: Sutton. 1984: Worrell. 1994) that a breakdown in the reciprocal action of the hamstrings and quadriceps results in hamstring strain. During running, as the knee approaches terminal extension. the hamstrings eccentrically contract to 
overcome the concentric contraction of the quadriceps, it is at this point that most hamstring strains occur (Shankman). Sutton attributed strains that occur in a open kinetic chain to a rapid deceleration in the lowering phase or a rapid acceleration of a stretched hamstring.

Two positions during the running phase potentially cause hamstring strain (Coole \& Geick. 1987). During the forward swing phase the hamstrings create tension. however. the eccentric contraction during deceleration causes even greater tension in the hamstrings as the quadriceps relax. causing strain (Coole \& Geick). The take off phase is cited for its role in strain because the musculature changes from a stabilizing role to a powerful flexor of the knee and extensor of the hip. Some (Coole \& Geick: Sutton. 1984) feel this causes a breakdown of the muscle. thus predisposing it to strain. Understanding the potential mechanisms of injury is crucial to prevention. evaluation. treatment. and rehabilitation of hamstring strain. Attempting to correct some congenital abnormalities. muscle imbalances. or poor running technique is critical to the prevention of injury Agre. 1985: Christensen \& Wiseman. 1972: Muckle. 1982).

\section{Muscle Strength}

Many researchers (Arnheim \& Prentice. 1994: Christensen \& IViseman. 1982: Öberg. Möller. Gillquist \& Ekstrand. 1986: Worrell \& Perrin. 1992. Yamamoto. 1993) contribute hamstrings weakness. hamstring/quadriceps strength ratio imbalance. or bilaterai muscle imbalance of either hamstrings or quadriceps to hamstring strain. There are many variables that can influence muscle strength. including age, experience. and training levels (Yamamoto). This makes it particularly hard to establish norms or ranges for strength and ratio. Shankman (1993) found that hamstring/quadriceps 
strength ratios vary from $1: 2$ or $1: 1$ at slower angular velocities and approach $80 \%$ as the angular velocity increases.

Liemohn ( 1978 ) conducted a prospective study using 27 participants on a Division I collegiate track team. He measured isometric hamstrings and quadriceps strength and flexibility. Seven of the 27 participants had mild or severe hamstring strains. Liemohn reported muscle imbalance was greater in the injured athletes. Left hamstring/quadriceps strength ratios were higher than the right hamstring/quadriceps strength ratios for the injured group when compared to the uninjured group. Five of the strains were to the left leg and two of the injuries were to the right leg. Leg dominance was not a predictor. but lead leg. take off leg, and front leg were significant predictors of which leg would experience hamstring strain.

Yamamoto (1993) conducted a study of Japanese college track and field athletes. He conducted the study to determine if weak hamstrings alone or a low hamstring/quadriceps strength ratio caused hamstring strain. Participants were tested isometrically for maximum voluntary contraction (MVC). Yamamoto measured knee tlexion and extension and hip tlexion and extension by placing a distal strap around the ankle at the height of the medial malleolus. Hip extension and hip flexion were measured a second time with the resistance strap placed around the patella. Incidence of strain was followed during two year period following the MVC exertion test. Yamamoto found the bilateral knee flexion MVC comparison was only significant if used as part of a MVC per body weight. Yamamoto concluded for track and field athletes low hamstring/quadriceps strength ratio was the leading factor in hamstring strain. 
Christensen and Wiseman (1972) studied collegiare track athletes. They isometrically measured bilateral knee flexion and extension strength. Athletes reported any incidence of hamstring strain to the tester.

Hamstring/quadriceps strength ratios were calculated for each athlete to determine if imbalance was significant. The researchers predicted five incidents of hamstring strain because of the hamstring/quadriceps strength ratio. Two athletes reported hamstring strain during the winter season. For this particular study the prediction rate was $40 \%$. Christensen and Wiseman predicted the predisposition of hamstring strain when bilateral isometric strength or hamstring/quadriceps strength ratios exceeded $10 \%$.

Hamstring/Quadriceps Strength Ratio

Zakas et al. (1995) examined the hamstring/quadriceps strength ratio in soccer and basketball players. The activities and movements required in soccer and basketball demand high strength and accurate muscular coordination. Sixty-one basketball players and 51 soccer players were tested isokinetically for hamstrings and quadriceps peak torque. Zakas separated the basketball players and soccer playeers bỵ division (I. II. III. and IV) and compared across division to determine which group had the highest peak torque at two angular relocities $60 \% / \mathrm{sec}$ and $180 \%$ sec. The national basketball team (highest division) had the greatest peak torque strength. The national team also had the highest hamstring/quadriceps strength ratio at all angular velocities. The division I soccer team (highest division) had the highest measurements for peak torque and hamstring/quadriceps strength ratio for all soccer players. A comparison of peak torque between soccer and basketball plavers indicated basketball plavers had significantly higher scores for 
flexion and extension at $60 \% / \mathrm{sec}$ and $180 \% / \mathrm{sec}$. However, when peak torque relative to body weight was compared the data failed to be significantly different. The possible reason for the highest division in each sport having the greatest peak torque values is that training intensity and year round practice allowing for greater strength and physical condition as the level of competition increases (Zakas et al.).

In a study of collegiate track athletes in Japan. Yamamoto (1993) examined the importance of strength and hamstring/quadriceps strength ratio. The ratios were obtained through isometric evaluation of knee flexor and extensor strength. A two year post-strength evaluation of the athletes reported the incidence of hamstring strain. The study indicated injured athletes had a significantly lower hamstring/quadriceps strength ratio than did the noninjured. Yamamoto reported a low hamstring/quadriceps strength ratio along with significantly lower maximum volume contraction as potential causes for strain to the injured group.

Morris. Lussier. Bell. and Dooley (1983) suggested that bilateral asymmetry is a predisposing factor to muscle strain. These authors isokinetically tested 12 NCAA Division I collegiate track athletes without a history of knee or thigh problems to determine hamstring/quadriceps strength ratio and peak torque. Bilateral testing occurred at angular velocities of $30^{\circ} .60^{\circ}$. $180^{\circ}$. $240^{\circ}$. and $300 \%$. The athletes were also tested isometrically through a full range from $50^{\circ}$ of flexion to $0^{\circ}$ (full extension). Isokinetic results indicated that as the speed of the isokinetic dynamometer increased the hamstring/ quadriceps strength ratio approached one. At $30 \% \mathrm{~s}$ and $60 \% \mathrm{~s}$ the ratios were .63 and .65 . respectively. The ratios increased to $.76, .83$. and .87 as the angular velocity increased from $180 \%$ s. $240 \%$ s. and $300 \%$ s. 
Relative to body weight. higher ratios occurred at the slow angular velocity $(30 \%$ s and $60 \%$ s) and decreased at the fast velocities $(80 \%$ s. $240 \%$ s, and $300 \%$ s). Morris et al. (1983) measured the isometric maximum at .79 of the body weight. They concluded that the hamstring/quadriceps strength ratio varies as the angular velocity varies.

Chin, So, Yuan. Li. and Wong (1994) evaluated the cardiorespiratory fitness. isokinetic strength, and hamstring and quadriceps strength ratio. The participants were elite Asian junior soccer players with a mean of seven years playing experience. They underwent a battery of tests including body composition. maximum aerobic power. flexibility, and isokinetic muscle strength. Participants were tested at $60 \%$ s and $240 \%$ to simulate slow and fast muscle work. Comparison of dominant and nondominant knee extensor strength was not significant, however the dominant leg knee flexor strength was significantly greater than the nondominant leg. Eighteen of 21 athletes had a nondominant to dominant leg muscle strength imbalance of $10 \%$ or greater. Eight players had low hamstring/quadriceps strength ratio at $60 \% \mathrm{~s}$ and 12 had low ratios at $240 \%$ s.

Stafford and Grana (1984) studied 60 collegiate football players to calculate hamstring/quadriceps strength ratios at speed of $90 \%$ s. $180 \%$, and $300 \%$ for dominant and nondominant legs. They tested participants at all three angular velocities and compared the peak torque measurements for hamstring/ quadriceps strength ratio and contralateral imbalances. Bilateral comparison of the quadriceps indicated that the dominant side was significantly stronger than the contralateral side. Similar comparison of the hamstrings indicated no significant imbalance. Both hamstring/quadriceps strength ratios approach a $1: 1$ ratio as the angular velocity increased. This 
study concluded the hamstrings play a stronger role as the velocity increases and the quadriceps are the more dominant muscle at lower angular velocities. Muscle strength and hamstring/quadriceps strength ratio are factors in hamstring strain (Arnheim \& Prentice. 1994: Christensen \& Wiseman. 1982: Öberg, Möller. Gillquist \& Ekstrand. 1986: Worrell \& Perrin, 1992. Yamamoto. 1993). The authors suggested the need for more prospective testing on a variety of sports and positions within those sports. Previously muscle strength was determined by the rertical jump (Zakas et al.. 1995), but with current access to isokinetic dynamometers. muscle strength and hamstring/quadriceps strength ratios can be assessed at varying, more sport specific angular velocities.

\section{Flexibility of the Hamstrings}

Ekstrand and Gillquist (1983b) examined the avoidability of soccer injuries. They examined player factors, equipment factors. playing surface. and rules as etiologies of injury. One hundred and thirteen soccer players were observed with one or more tight muscles: 44 plavers sustained rupture or tendinitis of the lower extremity muscles: 34 of the injured athletes had muscle tightness: 10 had normal flexibility. The 13 soccer players who sustained adductor rupture or tendinitis had less hip adductor range of motion than the uninjured group. There was no significant range of motion difference for the hamstring strained group compared to the uninjured group.

Krivikas and Feinberg (1996) studied 201 NCAA Division I college athletes to determine the relationship between ligamentous laxity and muscle tightness. Assessments for ligamentous laxity and muscle tightness were completed during preseason physicals. The muscles tested for flexibility were 
the iliotibial band. iliopsoas, rectus femoris, hamstrings, and gastrocnemiussoleus complex. Injury records were kept throughout the season on any back or lower extremity injury. Loss of practice and games were noted. Injuries were classified as to type and site.

They found sprains, strains, and overuse injuries were found in the male and the female participants and accounted for $83 \%$ of the injuries. Ankle injury was the most common injury followed by groin, hip, quadriceps, and hamstring strain. Of the 201 athletes, 83 men and 32 women sustained an injury during the season. There was greater ligamentous laxity and muscle tightness for males than for females. Krivikas and Feinberg found both flexibility and laxity as factors for hamstring strain, supporting the role of flexibility for protection against injury. "This study suggested that the detection of muscle tightness followed by implementation of a corrective stretching and rehabilitation program may be one way to reduce injury and justify the costliness of extensive pre-participation musculoskeletal screening" (Krivikas \& Feinberg, 1996, p.1143).

Ekstrand and Gillquist (1982) examined 180 senior male soccer players for past injury, current symptoms, and muscle tightness of the lower extremity. A control group of nonathletes was also tested for flexibility. Ekstrand and Gillquist used hip flexion with straight knee, hip adduction, hip extension, prone knee flexion, and dorsiflexion with straight knee as flexibility measures. There was no range of motion difference detected for the right and left legs. Soccer players were less flexible in hip adduction, hip extension, knee flexion, and dorsiflexion than the control group. Soccer players were more flexible in hip flexion than the control group. No significant difference between those who had previous injury in the past year 
and the rest of the athletes was indicated. Injuries sustained were fractures. contusions. sprains, dislocations. and strains. The majority of the injuries were to the lower extremity. Forty-five players had 62 strains to various musculotendinous units. Quadriceps strain accounted for $10 \%$ and hamstring strain were $9 \%$ of the lower extremity injuries. With anatomy, biomechanics. hamstring/quadriceps ratios. and muscle strength as possible factors $/ 9$ it is difficult to confirm only decreases in flexibility cause hamstring strain. Stretching and other exercises may improve performance and decrease the risk of strain.

Nielsen and Yde (1989) conducted a prospective study on a Danish soccer club. The athletes were evaluated for an eleven month period to determine the epidemiologic and traumatology of soccer injuries. The coach reported injuries on a monthly basis to the researchers. During the season 89 players incurred 109 injuries. $84 \%$ occurred in the lower extremity. Players sustained 19 strains- 8 hamstrings. 5 quadriceps. and 6 adductor. These thigh injuries were most common at the highest level of play. In this study strains required the shortest amount of time loss. Strains and ankle sprains were the most likely injuries to recur.

Worrell. Smith and Winegardner (1994) tested the effects of stretching on hamstring muscle performance of 19 university students. All participants were properly fitted to a Biodex (Biodex. Shirley. NY) isokinetic dynamometer. Each participant performed testing between $90^{\circ}$ of flexion to $0^{\circ}$ of extension at anguiar velocities of $60 \%$ s and $120 \%$ s. The participants had a warm up and familiarization period on the isokinetic dynamometer. Following a stretching (proprioceptive neuromuscular facilitation $[P N F]$ or static) program the isokinetic test was performed again. There were significant increases 
eccentrically at $60 \%$ s and $120 \%$ s and concentrically at $120 \%$ s. It was not mentioned which stretching group (PNF or static) had the greatest increases in peak torque. The PNF stretching group had a $1.5^{\circ}$ greater increase than the static stretch group for hamstring flexibility. There were significant increases in peak torque for $120 \%$ s and $60 \%$ s. yet the statistical power of the results ivas low because of interclass variability of participants (Worrell et al.). Isokinetic Measurement of Strength

Isokinetic measurement provides a valid and reliable method of determining muscle imbalances and/or weaknesses (Thomas. 1984). To guarantee reliability and validity of isokinetic testing the tester must control: 1) velocity of the test. 2) body position. 3) eccentric or concentric contraction. and 4) gravity effect torque or an acceptable alternative such as zero damping or angle specific testing (Ford. Bailey, Bablich \& Worrell. 1994). If strictly monitored isokinetic testing can provide a dynamic type of resistance. In isokinetic testing the angular velocity is controlled and an accommodating resistance during the entire range of motion is provided while allowing the velocity to remain constant.

Arnold. Perrin and Hellwig (1993) examined the reliability of isokinetic knee extension angle specific torques. Angle specific torques allow for muscle function assessment at a given speed. Amold et al.. studied 20 graduate and undergraduate female students. None of the participants had a history of knee injury or experience using isokinetic machines. Two sets of knee extension scores were recorded seven days apart. Each participant performed three submaximal and one maximal warm up repetition prior to testing on day one. Participants performed three maximal contractions at $60 \% / \mathrm{s}$ for the test. 
Arnold et al. averaged the three scores and extracted the angle specific torques at $30^{\circ} .60^{\circ}$. and $75^{\circ}$ of extension from the data. Testing procedures remained the same on the day of the re-test. The results were subjected to an analysis of variance (ANOVA) and calculated for intraclass correlation coefficients (ICC). The ICC for $30^{\circ}$ was .84 , at $60^{\circ}$ was .87 . and at $75^{\circ}$ was .83 . The standard error for $30^{\circ}, 60^{\circ}$ and $75^{\circ}$ was $7.50 \mathrm{Nm}, 7.65 \mathrm{Nm}$. and $7.35 \mathrm{Nm}$, respectively. The study indicated good reliability for all three angle specific torques at all of the joint positions.

Thomas (1984) examined torque levels for adult females and the effects of age and body size on the measure. Participants were 97 healthy females aged 20-61 years. Thomas conducted the testing on a Cybex II (Lumex. Inc. Bay Shore. NY) isokinetic dỹnamometer. Testing angular velocities were set at $60 \%$ and $240 \%$ s. Participants performed warm up repetitions and then following a rest period through maximal flexion and extension repetitions. Correlations were calculated for torque. weight. age, and height. Multiple regressions were used to determine the combined effect of age. height. and weight on mean torque values. Thomas only reported results for the left leg. Age was significantly correlated with torque values. As age, height. and weight were considered in the equation. age again had the greatest relationship with the torque values.

Wyatt and Edwards (198I) examined hamstrings and quadriceps torque values during isokinetic testing. Fifty men and 50 women. aged 25-34 years with no history of previous knee injury. cardiac abnormality, isokinetic training, or athletic experience past the junior college level participated in the study. All participants tested at angular velocities of $60 \% \mathrm{~s} .180 \% \mathrm{~s}$, and $300 \%$ on the Cybex II isokinetic dynamometer. Each participant performed 5 
to 10 practice repetitions at all angular veloctties followed by a 2 minute rest period before the testing program.

\section{Summary}

The review of literature outlined different topics associated with hamstring strain. The anatomy of the hamstrings (biceps femoris. semimembranosus. and semitendinosus) muscle group and their biomechanical role in running was explained. Sutton (1984) and Casperson and Kaverman (1982) noted fatigue and failure of the reciprocal action of the hamstrings and quadriceps muscles as possible factors that lead to hamstring strain. Yamamoto (1993) examined decreased hamstring/ quadriceps strength ratios as contributing factors of hamstring strain. Ekstrand and Gilquist (1982. 1983a. 1983b) examined a lack of flexibility and/or muscle breakdown due to the complex contractions of the hamstrings were outlined as potential factors causing hamstring strain.

Stafford and Grana (1984) examined tootball players to determine hamstring/quadriceps strength ratios and the variation in hamstring/ quadriceps strength ratios as angular velocitics changes. They found that as angular relocities increased so did the hamstring/quadriceps strength ratios. The hamstring/quadriceps strength ratios approached $1: 1$.

Arnold. Perrin. and Hellwig (1993) used isokinetic strength testing and Morris et al. (1983) used isometric strength testing to create hamstring/ quadriceps strength ratios to determine which was a more accurate form of measurement through a full range of motion. It was determined that an isokinetic dỵamometer would better facilitate this research. The isokinetic 
dynamometer was researched for its validity and reliability as a measurement tool.

The review of literature examined the anatomy and biomechanics of the hamstrings, hamstrings strength, hamstring/quadriceps strength ratios, flexibility of the hamstrings, and isokinetics strength testing. All topics discussed have an important role in the experimental design of this current study. 


\section{Chapter 3}

\section{METHODS}

In this chapter a description of the participants. apparatus. procedures. experimental design. and statistical analysis of the data used to measure hamstring/quadriceps strength ratios is provided. The purpose of this study was to examine peak torque of the hamstrings and quadriceps to determine if significant isokinetic strength ratio imbalance exists between the anterior and posterior thigh muscle in collegiate men's and women's soccer athletes with and without hamstring strain. and to conclude if there was a correlation between hamstring/quadriceps strength ratio imbalances and occurrence of hamstring muscle strain.

\section{Participants}

All +4 ( 22 male. 22 female) athletes from the 1997 San Jose State University men's and women's soccer teams rolunteered to participate in the study. Twenty-eight participants (12 male, 16 female) comprised the test sample. Sixteen potential participants were disqualified from participation for reporting that they were currently experiencing knee pain. chronic or acute thigh muscle strain. or were recovering from knee surgery in the previous three months. Seven females and one male were currently experiencing knee pain or had knee surgery within the previous six months. Three females and five males were removed from the study due to ongoing musculoskeletal injury. Three males and one female had hip flexor strains or weakness, two females had quadriceps strains. and two males had adductor strains. The mean height was $182.04=6.88$ centimeters $(\mathrm{cm})$ and the mean weight was $377.48 \pm$ 31.26 kilograms $(\mathrm{kg})$ for the males. The mean height was $166.95 \pm 4.90 \mathrm{~cm}$ and 
the mean weight was $299.33=34.41 \mathrm{~kg}$ for the females. The weight was reported in pounds from a scale that was calibrated on the day prior to the testing and converted to $\mathrm{kg}$ at a later time. The height was read from a wall scale in inches and later converted to $\mathrm{cm}$.

The participant test group was composed of athletes without reported hamstring strain in the previous six months. Student athletes were contacted about their participation at the final spring meeting following spring practice in May 1997. An Agreement to Participate (Appendix A) was mailed to each participant three weeks prior to the day of testing. Each participant arrived at the test site with the agreement signed or he or she was required to read and sign the agreement prior to inclusion in the study. Following agreement to participate. each participant was independently screened by a National Athletic Trainers' Association. Board of Certification. Inc. Certified Athletic Trainer to determine the presence of thigh and knee abnormality or laxity. Volunteers with chronic or acute inflammatory knee conditions. unrepaired meniscal lesions. rotary instability and history of enthesopathic disease such as gout were eliminated from the study as determined by a Personal and Health Questionnaire (Appendix B). Athletes with the aforementioned conditions were not allowed to participate because of the association of such conditions as potential causes of recurrent hamstring strains (Muckle. 1982).

\section{Apparatus}

Participants were tested using a calibrated Cybex II isokinetic dýnamometer (Cybex Division of Lumex Inc.. Ronkonkoma. NY 11799). This apparatus was designed to provide accurate stabilization. anatomically correct positioning. and accessories for testing the knee in flexion and extension. The 
Cybex II was located on the San Jose State University campus. The Cybex II was calibrated according to the Cybex II manual two different times: prior to the women's team testing and prior to the men's testing. Research using isokinetic testing indicated a brief to maximal warm up period, followed by low to high relocity testing order. and an average of three to seven repetitions (Aagaard et al.. 1995: Amold et al.. 1993: Stafford \& Grana. 1984: Thomas. 1984: Wyatt et al.. (981). Accuracy for the Cybex II is reported by Cybex International as $\pm 1 \%$ (Cybex. 1983).

\section{Procedures}

Participants wore comfortable shorts or pants to allow for maximum comfort and effort during testing. Participants were encouraged to drive to the test and refrain from exercise prior to testing to control for warm up or fatigue effects from running, walking, or riding a bicycle.

Upon arrival. an approved Human Participants-Institutional Review Board Agreement to Participate in Research form was returned to the researcher or a new form was read and signed by each participant (Appendix A). Participants then rilled out a Personal and Health Questionnatre (Appendix B). To reduce the haio effect and protect the privacy of the participants. all data were coded (Nielsen \& Yde. 1996). Participants randomly drew a number already coded for gender. The code number was recorded on all data forms for that participant. The chosen number was discarded to prevent it from being drawn by another participant. Prior to isokinetic testing, leg dominance was determined by asking participants to kick a ball that was placed on the floor (Stafford \& Grana. 1984). The leg chosen to kick the ball was recorded as the dominant leg. Participants were also measured for height. weight. and knee 
joint flexibility. Orthopedic evaluation to determine rotary instability was performed by a National Athletic Trainers' Association Certified Athletic Trainer. After examination the participants performed a five minute warm up on a stationary bike. Stretching techniques (Appendix $C$ ) were demonstrated for the hamstring and quadriceps. Muscles were statically stretched for 15 seconds. This procedure was repeated three times for each leg and each muscle group. Stretching technique and time were monitored by the Certified Athletic Trainer.

Following the tlexibility exercises. participants were asked to sit at a Cybex II in a position recommended by Cybex Incorporated. Each participant was tested using the same Protocol for Isokinetic Testing (Appendix D). All participants tested their dominant leg first. The axis of the movement arm was aligned with the lateral joint line of the participant. The shin pad was placed two inches above the medial malleolus or the participant's comfort level (Cybex Manual. 1983). The participant was secured with a Veicro strap around the shin pad. at the thigh. and around the torso. The arms were crossed against the chest to isolate the knee musculature (Cybex Manual. 1983). After positioning on the Cybex II apparatus. the Introduction to Isokinetic Testing (Appendix E) was read to the participant. Participants then performed three submaximal and three maximal warm up repetitions at $60 \%$ followed by a 30 second rest. Next the participant performed the maximal testing at the ivarm up speed. The Cybex II was set at zero damping prior to all warm up and maximal repetitions. Isokinetic strength of the hamstrings and quadriceps were measured at angular velocities of $60 \%$ s. $120 \%$ s. and $180 \%$ s. Following the maximal testing and before the next warm up there was a one minute rest period (Worrell et al.. 1994). At each angular velocity participants was asked to 
perform seven repetitions of knee extension and knee flexion. The dominant leg was tested first at angular velocities of $60 \%$ s. $120 \%$ s. and $180 \%$ s. The nondominant leg was tested following the maximal test at $180 \%$ s of the dominant leg. The nondominant leg was also tested at angular velocities of $60 \%$ s. $120 \%$ s, and $180 \%$ s. Participants were not visually or verbally encouraged during the maximal testing.

Injury evaluation of the athletes took place throughout the entire fall season (excluding post season play). For the purpose of this study a hamstring strain was defined as an incident that requires an athlete to miss a practice or a game. All injuries were recorded on an Injury Record (Appendix F). The number of practice and game hours was recorded on a Practice and Game Weekly Hour Log (Appendix G). At the conclusion of the 1997 San Jose State University soccer seasons the statistical analysis was performed on the data.

\section{Design}

A total of 28 men's and women's soccer players at San Jose State University comprised the study group. At the time of testing, all participants were asymptomatic of any injury affecting knee flexion or knee extension. The group was isokinetically tested at $60 \% \mathrm{~s}$. 120\%/s. and $180 \%$ s for hamstring and quadriceps strength. Following the Protocol for Isokinetic Testing to assess muscle strength (Appendix D) on the Cybex II. the channel strips were analyzed using the Cýbex Chart Data Card. Torque measurements were calculated for seven trials. The second through the sixth trials were averaged to determine mean torque (Welker. 1996). Mean torque was used to determine a hamstring/quadriceps strength ratio and assess individual hamstring and quadriceps strength for the dominant and nondominant legs. The 
hamstring/quadriceps strength ratio was determined by dividing the knee flexion mean torque strength by the knee extension mean torque strength.

Following calculation of the mean isokinetic strength measurements. all participants were evaluated through a fall soccer season. All hamstring strains that occurred as a result of San Jose State University soccer were evaluated and recorded by a certified athletic trainer.

\section{Analvsis of Data}

For statistical analysis. the means and standard deviations for hamstring/quadriceps strength ratio were generated for groups with and without hamstring strain. To assess the relationship between hamstring/quadriceps strength ratios and occurrence of hamstring strain a point biserial correlation was calculated (Huck. Cormier. \& Bounds. 1974). The point biserial was used to correlate the dichotomous variable (hamstring strain) with the continuous variable (hamstring/quadriceps strength ratio). The equation used for the point biserial correlation was taken from Huck et al. $(1974)$ and is as bollows:

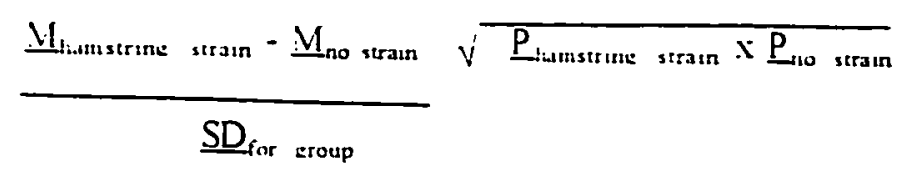

\section{Summarx}

Provided in this chapter is a description of the participants. apparatus. testing protocol, design. and analysis of data. The participants were San Jose State University men's and women's soccer players between the ages of 18 and 23 years old. There were 12 men and 16 women in the group. Participants were screened according to their Personal and Health Questionnaire. A Cybex 
II isokinetic dynamometer was used to measure hamstrings and quadriceps strength in this study. The testing protocol involved a general body warm up. stretching procedure. introduction to isokinetic testing, warm up on the Cybex II. and maximal testing on the Cybex II at three angular velocities of $60 \%$, $120 \%$ s. and 180\%. The above procedures allowed for the knee extensors and knee flexors to be isolated and studied independently. All data were recorded and analyzed for correlation using a point biserial correlation test. 


\section{Chapter +}

\section{RESULTS}

This study was conducted to examine peak torque of the hamstrings and quadriceps to determine if significant isokinetic strength ratio imbalance exists between the anterior and posterior thigh muscle in collegiatc men's and women's soccer athletes with and without hamstring strain. and to conclude if there was a correlation between hamstring/quadriceps strength ratio imbalances and occurrence of hamstring strain. The data were analyzed by using the SPSS* rersion for Windows 95 statistical package in the College of Applied Arts and Sciences Lab at San Jose State University.

The 29 ( 16 female. 12 male) participants that constituted the test sample had no history of knee or leg injury in the previous six months. had full hamstrings and quadriceps flexibility: and were cleared to participate in the study. Participants followed the test protocol which included warm up repetitions. followed by a brief rest period. then maximal repetitions followed by another rest period (Thomas. 1984). This same protocol was followed for every participant at all angular relocitics.

Descriptive statistics were used to answer questions about gender and injury- dominant leg and injury. dominant leg and gender. and hamstring/quadriceps strength ratio for those participants with and without a hamstring strain. Frequency distribution charts and cross tabulations were specific tests used to answer the questions.

A crosstabulation was performed to examine the occurrence of injury as tt relates to leg dominance. Twenty-two $(78.6 \%)$ participants were right leg dominant. five $(17.9 \%)$ participants were left leg dominant. and one (3.6\%) subject was equally dominant for the right and left legs. The subject that 
reported equal dominance did not kick the ball. The researcher was verbally informed by the female participant that she was equally dominant. Of the 5 left leg dominant participants. one incurred a strain injury to the left leg.

A cross tabulation was used to examine gender and leg dominance.

Twelve females and 10 males were right leg dominant. Three females and two males were left leg dominant and one female was equally dominant for both legs.

The men's team practiced for 106.25 hours over the course of the season ( 8.17 hours/week) and the women's team practiced for 108.25 hours $(9.02$ hours/week). Both teams played 20 games. lasting approximately 1.5 hours each. throughout the season. This accounted for 2.3 game hours/week for the men's team and 2.5 game hours/week for the women's team. The men's season was 1 week longer ( 13 weeks) than the women's season.

The following is a profile of the injured athlete. Of the total test group. one subject (3.6\% of the group) incurred a hamstring strain. This participant was a left leg dominant male. The injury occurred in the left hamstring. The difference between left leg hamstring/quadriceps strength ratio and right leg hamstring/quadriceps strength ratio was. 12. with the right leg having the higher hamstring/quadriceps strength ratio.

The means and standard deviations of hamstring/quadriceps strength ratio for the sample $(n=28)$ were $.85 \pm .11$ for the right leg and $.91=.13$ for the left leg. The means and standard deviations of hamstring/quadriceps strength ratios for those with and without hamstring strain for both legs are shown in Table 1 . 
Table 1. Hamstring/Quadriceps Strength Ratios for Participants With and Without Strain

\begin{tabular}{lcc} 
& Left H/Q ratio & Right H/Q ratio \\
without injury $(\mathrm{n}=27)$ & $.91 \pm .13$ & $.85 \pm .11$ \\
with injury $\quad(n=1)$ & $.87 \pm .00$ & $.99 \pm .00$ \\
\hline
\end{tabular}

Only one athlete was injured eliminating the possibility of running a parametric test. Since parametric assumptions were not met a point biserial correlation test was applied to the data. The point biserial equation was computed using a hand calculator. The point biserial correlation was -.06 for the left leg and .22 for the right leg when all angular velocities vere averaged. The point biserial correlation was calculated for both legs at each angular velocity to determine if a significant correlation existed at any of the angular velocities. The point biserial correlations for the left leg at $60 \% \mathrm{~s}$. $120 \%$ s. and $180 \%$ were .09 .01 . and .08 . respectuvely. The point biserials for the right leg were 18. 02. 21 for angular velocities of $60 \%$ s. $120 \%$ s. and $180 \%$ s. respectively. In order for there to be a strong correlation the point biserial correlation must approach +1 or -1 (Huck et al.. 1974). The point biserial correlations for the left leg were weak correlations and the right leg were weak to low (Huck et al.). None of the correlations were statistically significant.

The correlation between hamstring/quadriceps strength ratios and occurrence of hamstring strain was not statistically significant. However. due 
to the single injury there was not sufficient data to test the three null hypotheses.

The means and standard deviations for peak torque for males and females at the three angular velocities of $60 \%$ s, $120 \%$, and $180 \%$ s. were analyzed. The results are provided in Table 2 .

Table 2. Means and Standard Deviations for Peak Torque at $60 \% \mathrm{~s}$. 120\% $180 \% \mathrm{~s}$

\begin{tabular}{|c|c|c|c|c|}
\hline \multirow[t]{2}{*}{ Females } & \multicolumn{2}{|c|}{ Right Leg } & \multicolumn{2}{|c|}{ Left Leg } \\
\hline & Hamstrings & Quadriceps & Hamstrings & Quadriceps \\
\hline $60 \% / \mathrm{s}$ & $56.47 \pm 12.84$ & $72.13 \pm 16.16$ & $57.78 \pm 14.82$ & $72.45 \pm 17.12$ \\
\hline $120 \% \mathrm{~s}$ & $38.42 \pm 8.91$ & $43.52 \pm 21.38$ & $42.64 \pm 10.36$ & $42.64 \pm 12.68$ \\
\hline $180 \% \mathrm{~s}$ & $29.08 \pm 10.62$ & $30.71 \pm 11.71$ & $28.07 \pm 10.63$ & $28.61 \pm 11.27$ \\
\hline \multirow[t]{2}{*}{ Males } & \multicolumn{2}{|c|}{$\underline{\text { Right Leg }}$} & \multicolumn{2}{|c|}{ Left Leg } \\
\hline & Hamstrings & Quadriceps & Hamstrings & Quadriceps \\
\hline $60 \% \mathrm{~s}$ & $96.60 \pm 11.09$ & $118.34 \pm 22.89$ & $93.35 \pm 9.97$ & $119.01 \pm 17.92$ \\
\hline $120 \% \mathrm{~s}$ & $73.61 \pm 16.38$ & $82.81 \pm 26.66$ & $68.47 \pm 12.24$ & $81.42 \pm 20.31$ \\
\hline $180 \% / \mathrm{s}$ & $53.18 \pm 17.29$ & $56.20 \pm 21.69$ & $50.82 \pm 17.11$ & $54.87 \pm 23.47$ \\
\hline
\end{tabular}

Note All measurements are in $\mathrm{N} \bullet \mathrm{m}$.

The hamstring/quadriceps ratios for males and females were separated by leg and angular velocity. The ratios are listed in Table 3. 
Table : Hamstring/Quadriceps Ratios at $60 \%$ s. 120\%s and $180 \% \mathrm{~s}$

\begin{tabular}{|c|c|c|}
\hline \multirow[t]{2}{*}{ Females } & Right Leg & Left Leg \\
\hline & Hamstring/Quadriceps Ratio & Hamstring/Ouadriceps Ratio \\
\hline $60 \% \mathrm{~s}$ & $.80 \pm .14$ & $.82 \pm .09$ \\
\hline $120 \% \mathrm{~s}$ & $.90 \pm .12$ & $.93 \pm .11$ \\
\hline $180 \% / \mathrm{s}$ & $.96 \pm .11$ & $.99 \pm .13$ \\
\hline \multirow[t]{2}{*}{ Males } & Right Leg & Left Leg \\
\hline & Hamstring/Quadriceps Ratio & Hamstring/Quadriceps Ratio \\
\hline $60 \% \mathrm{~s}$ & $.83 \pm .09$ & $.79 \pm .10$ \\
\hline $120 \% \mathrm{~s}$ & $.93 \pm .17$ & $.86 \pm .13$ \\
\hline $180 \% \mathrm{~s}$ & $.98 \pm .17$ & $.97 \pm .16$ \\
\hline
\end{tabular}

Note All measurements are percentages.

Supplementary tnalvsis

A two-way repeated measures analysis of variance (ANOVA) was conducted to determine if significant differences In hamstring/quadriceps strength existed across angular velocities as well as the interaction between gender and the angular velocities $(60 \% \mathrm{~s}$. $120 \%$ s. and $180 \%$ s). No statistically significant difference was found between gender and angular velocity ( $F[1$. $26]=04 . R=.616)$. The main effect of angular velocities was statistically significant (Table t). 
Table 4 Repeated Measures ANOVA for Gender and Angular Velocity

Source of Variation

Right Leg

DF $\quad \underline{M S} \quad \underline{\text { Sig of } F}$

Gender

$\begin{array}{llll}l & 02 & .68 & +17\end{array}$

Error

$26 \quad .02$

Angular Velocity

$2 \quad .17 \quad 11.08 \quad .000^{*}$

Gender by Angular Velocity

$2 \quad .00 \quad .04$

Error

$52 \quad .02$

Left Leg

DF $\quad$ MS $\quad$ Sig of $F$

Gender

$\begin{array}{llll}1 & .03 & 1.10 & .305\end{array}$

Error

$26 \quad .03$

Angular Velocity

$2.21 \quad 26.8+.000^{*}$

Gender by Angular Velocity

$\begin{array}{lll}2 & .00 \quad .49\end{array}$

Error

$52 \quad .01$

* $\underline{p}<.05$

$\underline{\text { Summary }}$

The descriptive analyses of the data examined frequency distributions of means and standard deviations of hamstring and quadriceps strength and hamstrings/quadriceps strength ratios. Crosstabulations examined gender as it relates to dominant leg and dominant leg and strain. A point biserial correlation was used to assess the relationship between hamstring/quadriceps strength ratios and the occurrence of hamstring strain. A repeated measures 
ANOVA was performed to examine the interaction between angular relocities and gender and the differences across angular relocities. 


\section{Chapter 5 \\ DISCUSSION AND CONCLUSIONS \\ Discussion}

The purpose of this study was to examine peak torque of the hamstrings and quadriceps to determine if significant isokinetic strength ratio imbalance exists between the anterior and posterior thigh muscle in collegiate men's and women's soccer athletes with and without hamstring strain, and to conclude if there was a correlation between hamstring/quadriceps strength ratio imbalances and occurrence of hamstring muscle strain. Hamstring/ quadriceps strength ratio was used to determine muscle ratio imbalance.

The participants were male and female college soccer players from San Jose State University. The isokinetic testing on the Cybex II was conducted on the day prior to the 1997 soccer season beginning. Isokinetic testing was performed to obtain peak torque strength scores for both hamstring and quadriceps muscles at $60 \% \mathrm{~s}, 120 \% \mathrm{~s}$, and $180 \%$ s. Hamstring strain was evaluated by a Certified Athletic Trainer and occurred if the athlete missed an entire practice or game due to the injury.

Demographic information was noted to determine its role in hamstring injury. The participant's age. gender. height. weight. dominant leg, and number of game and practice hours was descriptively analyzed.

The hamstring/quadriceps strength ratios were calculated for each angular velocity and for each leg. The hamstring/quadriceps strength ratios increased as the angular velocity increased and approached a $1: 1$ ratio. This finding supported research by Morris et al. (1983) that as angular velocity increases so do hamstring/quadriceps strength ratios. 
Stafford and Grana (1984) observed that as the angular velocity increased the hamstringiquadriceps strength ratio approached a $1: 1$ ratio in college football plavers. The hamstring/quadriceps strength ratios of the collegiate soccer players also showed that as the angular velocity increased from $60 \%$ s to $180 \%$ the ratios neared $1: 1$. Shankman (1993) suggested that hamstring/quadriceps strength ratio should approach a $1: 1$ ratio as angular velocity-increases. In this study the ratios at all three velocities were above 75. which is acceptable for most athletes (Yamamoto. 1993).

The data collected failed to meet the assumptions needed for parametric statistical analysis because only one athlete received a hamstring strain. Thus. the data were subjected to a point biserial correlation test. The point biserial correlation was -06 for the left leg and .22 for the right leg when all three hamstring/quadriceps strength ratios were averaged. The point biserial correlation for the left leg at $60 \%$ s, $120 \%$ s. and $180 \%$ s was .09 .01 . and .08 respectively. The point biserial for the right leg was .18, .02, and .21 for angular relocities of $60 \%$ s. $120 \%$ s, and $180 \%$ s. respectively.

The repcated measures ANOVA examined a possible interaction between gender and the hamstring/quadriceps strength ratios at the three angular velocities. The ANOVA also examined if there was significant interaction between the three hamstring/quadriceps strength ratios reported for each leg. As predicted by Stafford and Grana (1984) there was a significant interaction across the three angular velocities.

Based on the findings of this study hamstring/quadriceps strength ratios do not correlate with hamstring strain injury for collegiate men's and women's soccer players. However. due to the lack of injured players. the hypotheses as stated in Chapter I could not be tested. 


\section{Weaknesses of the Study}

The weaknesses of the investigation included a lack of statistical power due to the low number of hamstring strains as defined in this study. The low number of participants did not allow for many hamstring strains to occur. Some of the participants were not familiar with the Cybex II isokinetic testing device. This may have restricted them from exerting a maximal effort during the test. The amount of time available (one day) to test the participants may have contributed to possible submaximal performance. The definition of hamstring strain in the literature (Agre. 1985: Arnheim \& Prentice. 1994: Booher \& Thibodeau. 1994: Ekstrand \& Gilquist. 1982: Inklaar. 1994: Worrell. 1995) was defined differently in each publication. Therefore. the definition of injury for this study was determined by the author with the assistance of the aforementioned literature. An hamstring injury that forces the athlete to limit his or her participation from a practice or a game due to pain or dysfunction should be considered a hamstring strain. The athlete does not have to completely miss practice or a game to have a hamstring strain. Finally. limutung the participants to only San Jose State University men's and women's soccer players limits the generalizability of the results.

Hamstring/quadriceps strength ratios at other colleges and/or universities may have had a stronger correlation with hamstring strain.

\section{Recommendations for Future Studies}

For luture studies on the role of hamstring/quadriceps strength ratio imbalance on the occurrence of hamstring strain in collegiate soccer players the following recommendations are made. The recommendations suggest changes in the participant pool. procedures. and methods. 
First. the results of this study indicate no significant muscle imbalance between the hamstring and quadriceps muscles in a group of male and female intercollegiate soccer plavers. There were differences in hamstring/ quadriceps strength ratios at some angular velocities, but they were not significant. A larger participant pool should be used to uncover significant differences in hamstring and quadriceps strength ratios. A larger group of participants could increase the number of hamstring strains.

Next. participants should be given the opportunity to become familiar with the isokinetic dynamometer prior to the testing. This should allow for comfort on the apparatus and guarantee maximal effort on the test day.

Third. participants should be tested over a longer period so that testing is not rushed. This presents a problem because of the limited days prior to the first day of practice that athletes are allowed to participate in their respective sports. This test day counted as a practice session toward the total allowed by the National Collegiate Athletic Association for both the men's and women's teams.

Fourth. a clearer definition of hamstring strain injurỵ must be developed and used. Even though only one subject exhibited hamstring pain or problems throughout the season. in the future a more scientific definition may be necessary. A clearer definition might allow some conditions that were not considered injuries before to be added to the injury data.

Fifth. the participants should be tested at three points during the season: prior to its beginning, at the midpoint, and at the conclusion. A repeated measures test of the isokinetic strength would allow for further analysis of the data and subsequently a comparison of the hamstring/ quadriceps strength ratios throughout the season. The data collected from 
repeated testing could increase descriptive analyses and provide more substantial information in the event a hamstring strain did not occur.

Sixth. the angular velocity test angular velocities should be faster for testing soccer players. The angular velocities should range from $60 \%$ s to $300 \%$ for soccer players.

Finally, using Cybex II with a computer will make retrieval of the data easier. Peak torque measurements for seven maximal quadriceps and hamstrings exertions at three different angular velocities for both legs were difficult to calculate by hand. The Cybex II used for this investigation was in good working condition. but it was in a crowded room and was not interfaced with a computer.

\section{Conclusions}

In the 1996 soccer season there were seven ( 5 males, 2 females) hamstring strains that occurred to players on the men's and women's soccer teams at San Jose State University. The cause of the strains was not examined. There are many factors that can contribute to hamstring strain: fatigue. biomechanics. decreased flexibility, hamstring weakness and hamstring/quadriceps strength ratio imbalance (Arnheim \& Prentice, 1994: Christensen \& Wiseman. 1982; Öberg, Möller, Gillquist. \& Ekstrand, 1986: Worrell \& Perrin. 1992: Yamamoto, 1993). This study was designed to specifically examine peak torque of the hamstring and quadriceps muscle groups to determine if significant hamstring/quadriceps strength ratio imbalance exists between the anterior and posterior thigh muscle in collegiate men's and women's soccer athletes with and without hamstring strain, and to 
conclude if there is a correlation between hamstringsiquadriceps strength ratio imbalances and occurrence of hamstring strain.

Men's and women's college soccer plavers were chosen for the study because they were easily accessed and there was no research that focused on intercollegiate soccer players. Previous studies examined the contributing factors to hamstring strain in elite soccer players, football players. track athletes. basketball players. junior college athletes, and untrained graduate students (Christensen \& Wiseman. 1972: Liemohn. 1978: Morris. Lussier. Bell \& Dooley. 1983: Nielsen \& Yde. 1989: Stafford \& Grana. 1984: Yamamoto. 1993: Zakas et al. 1995).

During the 1997 San Jose State University men's and women's soccer seasons. only one hamstring strain occurred. The strain occurred in a player that had a hamstring/quadriceps strength ratio difference of .12 in the leg that incurred the strain. The left leg was his dominant leg, yet the strain occurred there. It appeared that the hamstring/quadriceps strength ratio of his left leg correlated with the strain. but it was not statistically supported by the point biserial correlation test.

Decreased hamstring/quadriceps strength ratios were discussed by many researchers (Agre. 1985: Casperson \& Kaverman. 1982: Christensen \& Wiseman. 1972: Coole \& Geick. 1987: Shankman. 1993: Sutton. 1984: Worrell \& Perrin. 1992) as potential factors that cause hamstring strain. However. the statistical analysis of the current data did not support this.

Morris et al. (1983) examined track athletes and reported their hamstring/quadriceps strength ratios at angular relocities of $30 \% \mathrm{~s} .60 \% \mathrm{~s}$. $180 \%$ s. $240 \% \mathrm{~s}$. and $300 \%$. They reported the hamstring/quadriceps strength ratios at $.63, .65, .76, .83$, and .87. respectively. A comparison of the track 
athlete hamstring/quadriceps strength ratios and the collegiate soccer ratios of this study proved that the collegiate soccer players had higher hamstring/quadriceps strength ratios.

More research is needed in this area. The design of this study created the limitations for statistical power. The results did not support a significant correlation between hamstring/quadriceps strength ratio imbalance and the occurrence of hamstring strain in collegiate soccer players. Prior research has supported correlations among hamstring/quadriceps strength ratio imbalance and hamstring strain in other sports such as football. track, elite soccer. and basketball (Chin et al.. 1994: Morris et al. 1983: Öberg et al.. 1986: Worrell \& Perrin. 1992: Yamamoto. 1993: Zakas et al., 1995). Future research is needed to examine the same variables with a larger sample of intercollegiate soccer players. This research is the first step in examining United States collegiate soccer players and the role of hamstring/quadriceps strength ratio imbalance to hamstring strain. Hopefully other researchers will use this investigation as a foundation for future studies. 


\section{REFERENCES}

AaGaard. P.. Simonsen. E.. Trolle. M.. Bangsbo. J.. \& Klausen. R. (1995) Isokinetic hamstring/quadriceps strength ratio: influence from joint angular velocity: gravity correction and contraction mode. Scandinavian Phvsiological Societr: $15(4) .+21-+27$.

Agre. J. (1985). Hamstring injuries. Sports Medicine, 2, $21-33$.

Arnheim. D.. \& Prentice. W. (1994). Principles of athletic training. St. Louis: Mosby-Year Book. Inc.

Arnold. B.. Perrin. D.. \& Hellwig, E. (1993). The reliability of three isokinetic knee-extension angle-specific torques. Journal of Athletic Training. 28(3). 227-229.

Booher. J.. \& Thibodeau. G. (1994). Athletic injury assessment. St. Louis: Mosby-Year Book. Inc.

Brotzman. S. (1996). Clinical orthoepaedic rehabilitation. St. Louis: Mosby-Yearbook. Inc.

Burkett. L. (1978). Causative factors in hamstring strain. Medicine and Science in Sports, 2(1). 39- +2 .

Casperson. P..\& Kaverman. D. (1982). Groin and hamstring injuries. Athletic Training. $17(1) .+3-45$.

Chin. M.. So. R.. Yuan. Y.. Li. R.. \& Wong, A.(1994). Cardiorespiratory fitness and isokinetic muscle strength of clite Asian junior soccer players. The Journal of Sports Vedicine and Phrsical Fitness. $34(3), 250-257$

Christensen. C.. \& Wiseman. D. (1972). Strength. the common variable in hamstring strain. Athletic Training.7 2. 36-40.

Cook. J. (1991). Conversion factors. New York: Oxford University Press.

Coole. W.. \& Geick. J.(1987). An analysis of hamstring strains and their rehabilitation. The Journal of Orthopaedic and Sports Phrsical Theraps: 9 (2). $77-85$.

Cybex. Division of Lumex. Inc. (1983). Isolated joint testing and exercise: A handbook for using Cybex II. 67-70.

Elliott. B.. \& Blansky. B. (1979). The synchronization of muscle activity and body segment movements during a running cycle. Medicine and Science in Sports. 11, 322-327. 
Ekstrand. J.. \& Gillquist. J. (1982). The frequency of muscle tightness and injuries in soccer plavers. The American Journal of Sports Medicine. 10(2).
$75-78$.

Ekstrand. J.. \& Gillquist. J. (1983a). Soccer injuries and their mechanisms: a prospective study. Medicine and Science in Sports and Exercise. $15(3) .267-270$.

Ekstrand. J.. \& Gillquist. J. (1983b). The avoidability of soccer injuries. International Journal of Sports Medicine $+122-128$.

Ford. W.. Bailey. S., Bablich. K.. \& Worrell. T. (1994) The effect of hip position on gravity torque. Medicine and Science in Sports and Exercise, 26(2).
$230-234$. Fried. T.. \& Lloyd. G. (1992). An overview of common soccer injuries.
Sports Medicine. $14(4) .270-295$.

Huck. S.. Cormier. W.. \& Bounds. W. (1974) Reading statistics and research New York: Harper \& Row Publishers.

Inklaar. H. (1994). Soccer injuries: Incidence and severity. Sports Medicine 18 \$5-73.

Krivickas. L.. \& Feinberg, J. (1996) Lower extremity injuries in college athlete: relation between ligamentous laxity and lower extremity muscle tightness. Archives of Phvsical Medicine and Rehabilitation, 77, 1139-1143.

Liemohn. W. (1978). Factors related to hamstring strains. Journal of Sports Medicine. 18 71-76.

Morris. A.. Lussier. L.. Bell. G.. \& Dooley. J. (1983). Hamstring/ quadriceps strength ratios in collegiate middle-distance and distance runners. The Phrsician and Sports Medicinc, 11(10). 71 - 77.

Moss. C.. \& Wright. P. (1993) Comparison of three methods of assessing muscle strength and imbalance ratios of the knee. Journal of Athletic Trainıng. 28(1). 55-58.

Muckle. D. (1982). Associated factors in recurrent groin and hamstring injuries. British Journal of Sports Medicine. 16(1). 37-39.

Nielsen. A.. \& Yde. J. (1989). Epidemiology and traumatology of injuries in soccer. The American Journal of Sports Medicine, 17(6). 803-807.

Öberg. B.. Möller. M.. Gillquist. J.. \& Ekstrand. J. (1986). Isokinetic torque ievels for knee extensors and knee flexors in soccer players. International Journal of Sports Medicine, ? 50-53. 
Shankman. G. (1993). Hamstring training: injury prevention and care. National Strength and Conditioning Association Journal, 15(4). 37-41.

Stafford. M., \& Grana. IV (1984). Hamstring/quadriceps ratios in college football players high velocity evaluation. The American Journal of Sports Medicine. $12(3)$.

Sutton. G. (1984) Hamstrung by hamstring strains. Journal of Orthopaedic and Sports Physical Therapy, 5(4). 184-195.

Thomas. J.. \& Nelson. J. (1996). Research metheds in phrsical activity. Illinois: Human Kinetics.

Thomas. L. (1984). Isokinetic torque levels for adult females: effects of age and body size. The Journal of Orthopaedic and Sports Phvsical Therapv
6 (1), 21- 24 .

Thompson. C. (1994). Manual of structural kinesiology St. Louis: Mosby-
Book. Inc. Year Book. Inc.

Welker. E. (1996). Lower leg strength in athletes with and without exercise induced leg pain. Unpublished master's thesis. San Jose State University.

Worrell, T. (1994). Factors associated with hamstring injuries. Sperts Medicine, $7(5), 338-3+5$.

Worrell. T.. \& Perrin. D. (1992). Hamstring muscle injury: The influence of strength. Ilexibility. warm up. and fatigue. Journal of Orthopaedic and Sports Phisical Theraps: 16(1). 12-18.

Worrell. T.. Smith. T.. \& Winegardner. J. (1994). Effect of hamstring stretching on hamstring muscle performance. Journal of Orthopaedic and Sports Phisical Therapr. 20(3). 154-159.

Wyatt. M.. \& Edwards. A. (1981). Comparison of quadriceps and hamstring torque values during isokinetic exercise. The Journal of Orthopaedic and Sports Phrsical Therapr; $3(2)$. 48-56.

Yamamoto. T. (1993). Relationship between hamstring strains and leg muscle strength. The Journal of Sports Medicine and Physical Therapy $33(2)$,
194-199.

Zakas. A.. Mandroukas. K.. Vamvakoudis. K., Christoulas. K.. \& Aggelopoulou. N. (1995). Peak torque of quadriceps and hamstring muscles in basketball and soccer plavers of different divisions. Journal of Sports Medicine
and Phusical Fitness. $35(3)$. 199-205. 


\section{Appendix A \\ Agreement to Participate in Research}

Responsible Investigator: Dawn A Carter. ATC. Graduate Student

Title of Study: The Effect of Hamstring and Quadriceps Muscle Imbalance on Hamstring Strain in Collegiate Soccer Players

I. volunteer to participate in a research study using maximal isokinetic strength to examine the effect of muscle imbalance on hamstring strain. I understand the testing will be performed in one session in the Human Performance Department at San Jose State University. Prior to testing. I will complete a personal and health questionnaire. My height. Weight. dominant and nondommant legs will be assessed prior to testing. A five minute warm up on a stationary bicycle will be followed by hamstring and quadriceps stretching. After a warm up at the current testing velocity and a one minute rest a set of five maximal repetitions will be performed. Then a rest period of two minutes will occur before the next warm up period. This procedure will be followed at all testing angular velocities of $30 \%$ sec. $90 \% / \mathrm{sec}$. and $180 \%$ sec.

I understand that testing will be performed and monitored by a National Athletic Trainers' Association certified athletic trainer (ATC) with experience in isokinetic testing. I understand that joint and/or muscular discomfort may occur during testing. Cardiopulmonary dysfunction may also occur. Potential benefits of participation may be knowledge of strength level of my dominant and nondominant knee and knowledge and familiarization of isokinetic testing.

Initials: 
I understand that there will be no alternative method of testing, no compensation for participation. and my withdrawal from the study will incur no penalty.

I am aware that the results of this study may be published. but that my confidentiality will be maintained. All results containing my identification will remain in a locked cabinet and will be destroyed after the study is completed.

Any questions. comments. or concerns may be directed to the Responsible Investigator at (408) 279-5762. Complaints regarding this study can be directed to Dr. James Bryant. Chair. Human Performance Department at (408) 924-3010. Questions or complaints about the research. participant rights. or study related injury can be directed to Serena Stanford. Ph.D.. Associate Academic Vice President for Graduate Studies and Research at (408) 924-2480.

I understand that my participation in this study is roluntary and by signing and dating below indicate that I have received a copy of this consent form and that my consent is given voluntarily.

Participant's Signature

Date

Participant's Printed Name

Investigator's Signature

Date 


\section{Appendix B \\ Personal and Health Questionnaire}

Identification Number

Personal

Name

Age__ Sex

Local Address

Local Phone

Work Phone

Permanent Address

Phone Number

Physician Name

Physician Phone

Who to Contact in Case of Emergency

Relationship

Phone Number

\section{Healch}

Height

Weight

Dominant leg

Joint Pain

Mark an " $\mathrm{X}$ " if you are currently experiencing pain in any of the following: ankle knee hip back wrist fingers elbow
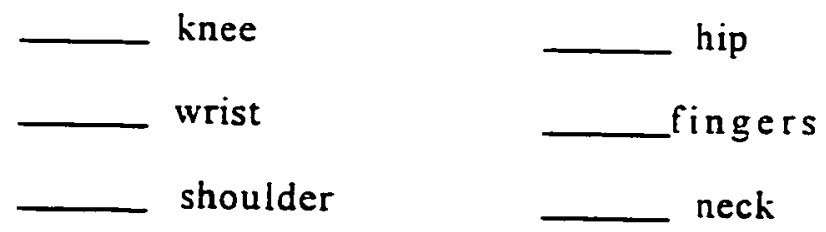
Mark an " $\mathrm{X}$ " if you are currently experiencing any of the following: gout - rotary instability of knee

unrepaired meniscal lesion Mark an " $\mathrm{X}$ " if you have experienced any of the following in the past three
months: limited knee range of motion

- hamstring strain knee surgery ankle sprain lower extremity fracture

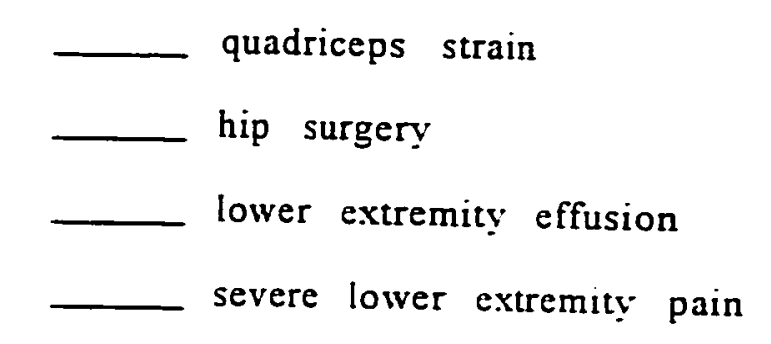

Have you ever underwent surgery on your lower extremity?

If yes. what for?

when? 


\section{Appendix $C$ \\ Stretching Techniques}

\section{Quadriceps Muscle Group}

l. Stand with one foot on the ground. grasp the ankle of the other leg and pull toward buttocks.

2. Hold stretch for 15 seconds.

3. Relax.

4. Alternate to other leg and repeat steps one through three.

5. Continue to alternate until each quadriceps has been stretched three times.

\section{Hamstring Muscle Group}

l. Sit on table with one leg hanging off the side.

2. While keeping the leg on the table straight, bend forward at the waist without arching the back.

3. Hold stretch for 15 seconds.

t. Relax.

5. Alternate to the other leg and repeat steps one through four.

6. Continue to alternate until each hamstring has been stretched three times. 


\author{
Appendix D \\ Protocol for Isokinetic Testing
}

1. Welcome participants

2. Complete consent and personal/health questionnaires

3. Record height and weight

4. Determine dominant leg

5. Warm up on stationary bicycle

6. Secure participant on Cybex II

7. Align dynamometer axis to lateral joint line

8. Introduction to Isokinetic Testing

9. Warm up at $60 \%$ s (3 submaximal and 3 maximal)

10. Rest (30 seconds)

11. Maximal testing at $60 \% / \mathrm{s}$ ( 7 repetitions)

12. Rest (one minute)

13. Warm up at $120 \%$ s (3 submaximal and 3 maximal)

14. Rest (30 seconds)

15. Maximal testing at $120 \%$ s $(7$ repetitions $)$

16. Rest (one minute)

17. Warm up at $180 \%$ s ( 3 submaximal and 3 maximal)

18. Rest (30 seconds)

19. Maximal testing at $180 \%$ s ( 7 repetitions)

20. Test contralaterai leg

21. Record test scores

22. Explanation of test scores to participants 


\section{Appendix E \\ Introduction to [sokinetic Testing}

The Cybex II unit is designed to provide maximal stability during isokinetic testing. It is widely used in rehabilitation and research. This experiment is composed of three maximal exertion tests for each knee. Each test will include a warm up and maximal exertion followed by a rest period.

You will be asked to perform three submaximal and three maximal repetitions followed by a 30 second rest. Following the rest period. seven maximal repetitions will be performed at the same warm up velocity. The maximal exertion will be followed by a one minute rest. This procedure will be followed for maximal testing at all three angular velocities and for both legs. During the test if you experience discomfort or pain or wish to stop the test. immediately notify the tester.

Important details to remember during testing:

* No verbal or visual encouragement will be given during the test.

* Keep arms crossed against chest during testing.

* Avord excess trunk movement during test.

* Push up and pull down as hard and as fast as you can throughout the entire range of motion. 


\section{Appendix $F$}

Injury Record

Name:

Sport:

Date of Injury:

Number of limited practices:

Number of missed practices:

Number of limited games:

Number of missed games:

Number of day post injury that full return to activity occurred:

Evaluation performed by: certified/student

Record kept by: certified /student

Please attach a copy of the original injury report 


\author{
Appendix $G$ \\ Practice and Game Weekly Hour Log
}

Week

Number of practice hours:

Number of game hours:

* Scrimmages against other teams will be considered game hours.

* Intersquad scrimmages will be logged as practice hours. 

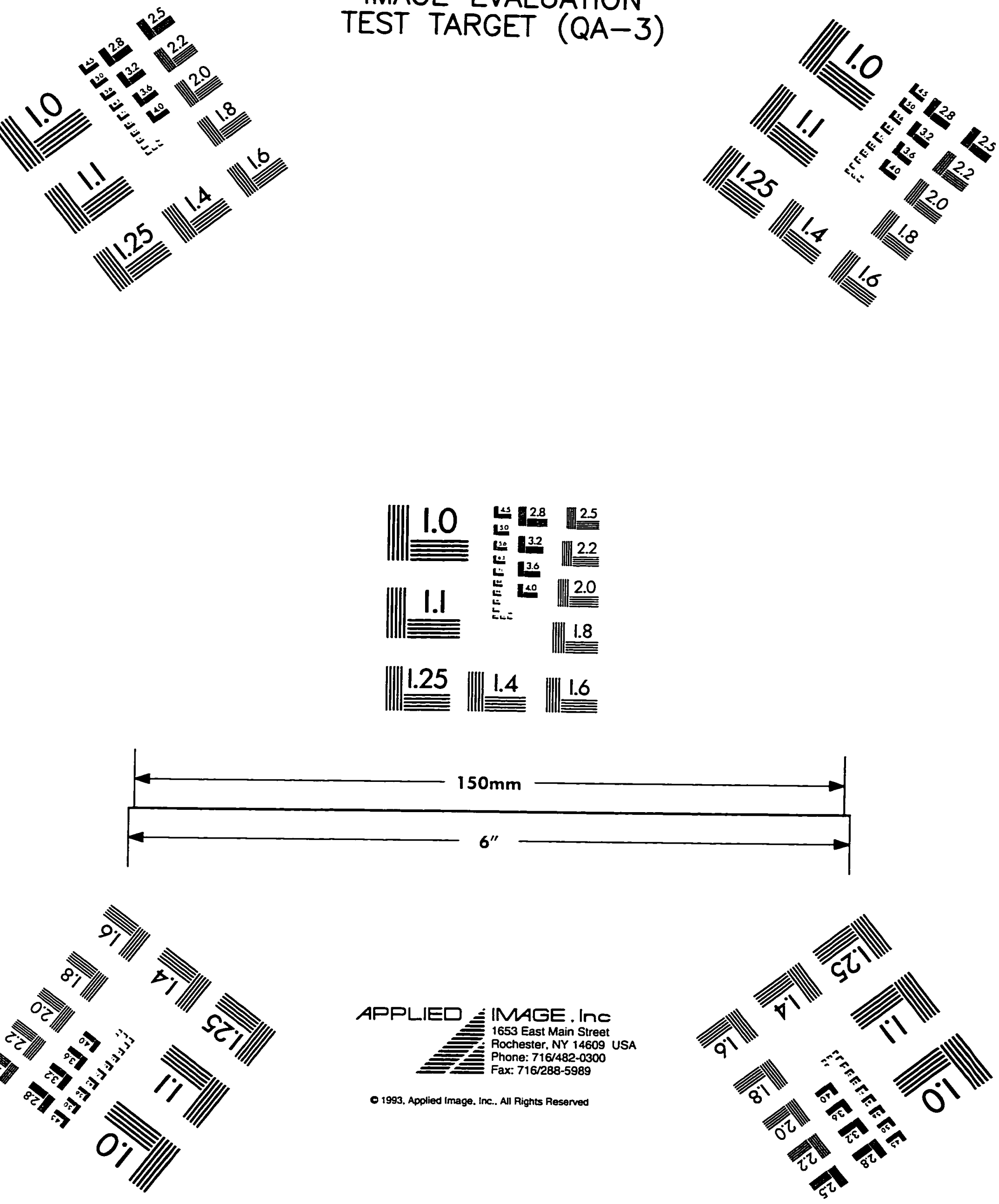